Article

\title{
Chiral Separation and Determination of Etoxazole Enantiomers in Vegetables by Normal-Phase and Reverse-Phase High Performance Liquid Chromatography
}

\author{
Ping Zhang ${ }^{1,2,3, *, \dagger}$, Yuhan He ${ }^{1,2, \dagger}$, Sheng Wang ${ }^{1,2}$, Dongmei Shi ${ }^{1,2}$, Yangyang $\mathrm{Xu}^{1,2}$, \\ Furong Yang ${ }^{1,2}$, Jianhao Wang ${ }^{1,2}$ and Lin $\mathrm{He}^{1,2,3, *}$ \\ 1 Key Laboratory of Entomology and Pest Control Engineering, College of Plant Protection, \\ Southwest University, Chongqing 400715, China; hm20161027@163.com (Y.H.); zpcauz@163.com (S.W.); \\ shidm48@163.com (D.S.); zp8708@163.com (Y.X.); yfr200111@163.com (F.Y.); ping17028@gmail.com (J.W.) \\ 2 Academy of Agricultural Sciences, Southwest University, Chongqing 400715, China \\ 3 State Cultivation Base of Crop Stress Biology for Southern Mountainous Land of Southwest University, \\ Southwest University, Chongqing 400715, China \\ * Correspondence: pingz@swu.edu.cn (P.Z.); helinok@vip.tom.com (L.H.); \\ Tel.: +86-23-68251514 (P.Z.); +86-23-68254105 (L.H.) \\ + These authors contributed equally to this paper.
}

Received: 17 June 2020; Accepted: 6 July 2020; Published: 9 July 2020

\begin{abstract}
The chiral separation of etoxazole enantiomers on Lux Cellulose-1, Lux Cellulose-3, Chiralpak IC, and Chiralpak AD chiral columns was carefully investigated by normal-phase high performance liquid chromatography and reverse-phase high performance liquid chromatography (HPLC). Hexane/isopropanol, hexane/n-butanol, methanol/water, and acetonitrile/water were used as mobile phase at a flow rate of $0.8 \mathrm{~mL} / \mathrm{min}$. The effects of chiral stationary phase, mobile phase component, mobile phase ratio, and temperature on etoxazole separation were also studied. Etoxazole enantiomers were baseline separated on Lux Cellulose-1, Chiralpak IC, and Chiralpak AD chiral columns, and partially separated on Lux Cellulose-3 chiral column under normal-phase HPLC. However, the complete separation on Lux Cellulose-1, Chiralpak IC, and partial separation on Chiralpak AD were obtained under reverse-phase HPLC. Normal-phase HPLC presented better resolution for etoxazole enantiomers than reverse-phase HPLC. Thermodynamic parameters, including $\Delta H$ and $\Delta S$, were also calculated based on column temperature changes from $10^{\circ} \mathrm{C}$ to $40{ }^{\circ} \mathrm{C}$, and the maximum resolutions $\left(R_{\mathrm{s}}\right)$ were not always acquired at the lowest temperature. Furthermore, the optimized method was successfully applied to determine etoxazole enantiomers in cucumber, cabbage, tomato, and soil. The results of chiral separation efficiency of etoxazole enantiomers under normal-phase and reverse-phase HPLC were compared, and contribute to the comprehensive environmental risk assessment of etoxazole at the enantiomer level.
\end{abstract}

Keywords: etoxazole; chiral separation; enantiomers; risk assessment; HPLC

\section{Introduction}

Chiral pesticides have become a hotspot in the field of pesticide research. About $30 \%$ of commercial pesticides are chiral [1,2]. However, most commercial chiral pesticides are sold in the racemate form. Enantiomers of chiral pesticide have almost the same physical and chemical properties in achiral environments and generally different properties in chiral environments, including biological activity, metabolism, degradation, and toxicity [3-9]. With the increasing number of synthesized and registered 
chiral pesticides introduced to market, it is urgent and necessary to investigate the environmental fates and toxicological risks of chiral pesticides at the enantiomer level.

Etoxazole [(RS)-5-tert-butyl-2-[2-(2,6-difluorophenyl)-4,5-dihydro-1,3-oxazol-4-yl]phenetole, CAS 153233-91-1 (Figure 1)] is a diphenyloxazole acaricide used to control various mites on vegetables, flowers, fruits, grass, etc. in agriculture. The mode of action (MoA) of etoxazole is to affect adult egg development by inhibiting chitin biosynthesis, thus it is used against nymphs, mite larvae, eggs, and is safe for adult mites [3,10-13]. Etoxazole has an asymmetric chiral carbon atom in its chemical structure and consists of two enantiomers ( $R$-etoxazole and $S$-etoxazole, at a ratio of 1:1) [3]. In recent years, etoxazole residue has been reported in soil, berry, apple, orange, and vegetables [13-16], which poses a high risk for human and environmental health.

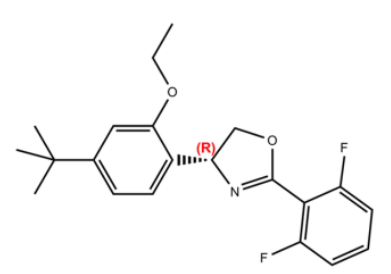

R-etoxazole

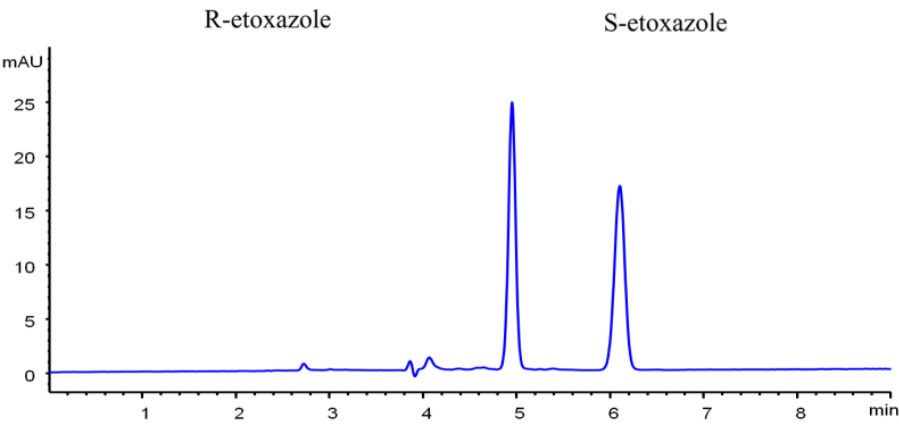

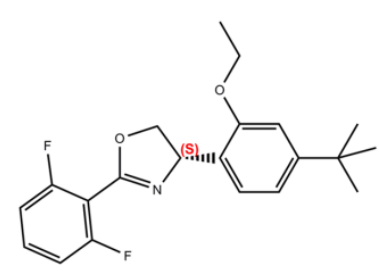

S-etoxazole

Figure 1. Chemical structure and chromatogram of etoxazole enantiomers on a Lux cellulose- 3 column with an $\mathrm{ACN} / \mathrm{H}_{2} \mathrm{O}$ ratio of $70 / 30$ at $40{ }^{\circ} \mathrm{C}$ under reverse-phase conditions.

Enantiomer separation of chiral pesticides is the first step in enantiomer risk assessment. Many methods have been reported for chiral separation, including normal-phase high performance liquid chromatography (NP-HPLC) [17], reverse-phase high performance liquid chromatography (RP-HPLC) [18,19], gas chromatography (GC) [20], capillary electrophoresis (CE) [21], supercritical fluid chromatography (SFC) [22,23], thin-layer chromatography (TLC) [24], micellar electrokinetic chromatography (MEKC) [25,26], capillary electro-chromatography (CEC) [27], and ultraperformance convergence chromatography (UPCC) [28]. HPLC, SFC, and UPCC have become the most effective and widely used approaches for chiral separation and enantiomer detection because numerous chiral stationary phases (CSPs) can be used [29], especially polysaccharide-based CSPs, including amylose-tris-(3,5-dimethylphenylcarbamate), cellulose-tris-(3,5-dimethylphenylcarbamate), cellulose-tris-(3,5-dichlorophenylcarbamate), cellulose-tris-(4-chloro-3-methylphenylcarbamate), etc., and cyclodextrin-based CSPs, including $\beta-\mathrm{CD}, \gamma-\mathrm{CD}$, and other derivatives such as $\beta-\mathrm{OH}, \alpha-\mathrm{PM}$, $\beta$-PM, and $\gamma$-PM [27].

The separation methods of etoxazole enantiomers include reverse-phase HPLC [30], normal-phase HPLC [31], ultraperformance liquid chromatography (UPLC) [32], ultraperformance liquid chromatography tandem mass spectrometry (UPLC-MS/MS) [3], and gas chromatography (GC) [15]. However, the systematic comparison of chiral separation of etoxazole enantiomers under normal-phase HPLC and reverse-phase HPLC has not been investigated. In our study, etoxazole enantiomers were separated on Lux Cellulose-1, Lux Cellulose-3, Chiralpak IC, and Chiralpak AD chiral columns under normal-phase and reverse-phase conditions. Baseline separation on Lux Cellulose-1, 
Chiralpak IC, and Chiralpak AD columns, and partial separation on Lux Cellulose-3 were achieved under normal-phase HPLC. Furthermore, etoxazole enantiomers were completely separated on Lux Cellulose- 1 and Chiralpak IC, and partially separated on the Chiralpak AD column under reverse-phase conditions. The effects of the chiral stationary phase, mobile phase component, mobile phase ratio, temperature, and thermodynamic parameters on resolution were also carefully investigated. Moreover, the optimized method was successfully applied to analyze etoxazole enantiomers in cucumber, cabbage, tomato, and soil. Such results systematically compared the chiral separation of etoxazole enantiomers under normal-phase and reverse-phase HPLC and contribute to the comprehensive environmental risk assessment of etoxazole at the enantiomer level.

\section{Results and Discussion}

\subsection{Chiral Separation of Etoxazole Enantiomers}

The chiral separation of etoxazole enantiomers was performed on normal-phase HPLC and reverse-phase HPLC (Figure S1). Table 1 lists the separation results, which include retention factor $\left(k_{1}\right.$ and $\left.k_{2}\right)$, selectivity factor $(\alpha)$, and resolution factor $\left(R_{\mathrm{S}}\right) . R_{\mathrm{S}}>1.5$ was considered as baseline separation. When hexane/isopropanol (HEX/IPA) was used as mobile phase under normal-phase HPLC, etoxazole enantiomers could be baseline separated on Lux Cellulose-1, Lux Cellulose-3, Chiralpak IC, and Chiralpak AD chiral columns. The maximum $R_{\mathrm{S}}$ on Lux Cellulose-1 (98/2), Lux Cellulose-3 (98/2), Chiralpak IC (90/10), and Chiralpak AD (90/10) were 4.50, 3.14, 13.21, and 15.45, respectively. Chiralpak AD had the best separation efficiency for etoxazole enantiomers under normal-phase HPLC with HEX/IPA as mobile phase. When hexane/ $n$-butanol $(\mathrm{HEX} / \mathrm{BuOH})$ was used as mobile phase, etoxazole enantiomers got a baseline separation on Lux Cellulose-1, Chiralpak IC, and Chiralpak AD columns, and partial separation on the Lux Cellulose-3 column. The maximum $R_{\mathrm{S}}$ on Lux Cellulose-1 (98/2), Lux Cellulose-3 (98/2), Chiralpak IC (95/5), and Chiralpak AD (98/2) columns was 2.46, 1.18, 14.98, and 8.41, respectively. Moreover, the separation efficiency of Chiralpak IC and Chiralpak AD were much better than that of Lux Cellulose-1 and Lux Cellulose-3, which indicated the 3,5-dichlophenyl carbamate group in Chiralpak IC and Chiralpak AD chiral columns had better chiral recognition for etoxazole enantiomers under normal-phase HPLC conditions. In general, a lower proportion of alcohol led to a longer elution time and better resolution under normal-phase HPLC. In accordance with this phenomenon, the retention factor $(k)$ and resolution factor $\left(R_{\mathrm{s}}\right)$ increased with decreasing ratio of alcohol in the mobile phase.

When methanol/water $\left(\mathrm{MEOH} / \mathrm{H}_{2} \mathrm{O}\right)$ was used as the mobile phase under reverse-phase conditions, etoxazole enantiomers could be baseline separated on Lux Cellulose-1, Chiralpak IC and partially separated on Chiralpak AD columns. Lux Cellulose-3 had no separation capability for etoxazole enantiomers. The maximum $R_{\mathrm{s}}$ on Lux Cellulose-1 (85/15), Chiralpak IC (80/20), and Chiralpak $\mathrm{AD}(85 / 15)$ were $2.68,5.84$, and 1.22 , respectively. Chiralpak IC had the best separation efficiency for etoxazole enantiomers under reverse-phase conditions when using $\mathrm{MEOH} / \mathrm{H}_{2} \mathrm{O}$ as the mobile phase. When acetonitrile/water $\left(\mathrm{ACN} / \mathrm{H}_{2} \mathrm{O}\right)$ was used as the mobile phase, etoxazole enantiomers achieved baseline separation on Lux Cellulose-1, Lux Cellulose-3, Chiralpak IC, and partial separation on Chiralpak AD columns. The maximum $R_{\mathrm{S}}$ on Lux Cellulose-1 (90/10), Lux Cellulose-3 (60/40), Chiralpak IC (60/40), and Chiralpak AD (60/40) were 3.94, 6.30, 9.40, and 1.02, respectively. Different separation capabilities were observed even on the same chiral column, when $\mathrm{MEOH} / \mathrm{H}_{2} \mathrm{O}$ and $\mathrm{ACN} / \mathrm{H}_{2} \mathrm{O}$ were used as the mobile phase. Methanol is both a hydrogen bond donor and acceptor, whereas acetonitrile is only a weak hydrogen bond acceptor. Therefore, the different separation abilities of methanol and acetonitrile may be induced by different hydrogen bond interactions involved in the mobile phase, etoxazole enantiomers, and the chiral stationary phase. In general, a lower proportion of organic solvent led to a longer elution time and better resolution in reverse-phase HPLC. In accordance with this phenomenon, the retention factor $(k)$ and resolution factor $\left(R_{\mathrm{S}}\right)$ of etoxazole enantiomers increased with decreasing ratio of methanol or acetonitrile in the mobile phase in most cases. However, 
the $R_{\mathrm{S}}$ on Lux Cellulose- 1 increased with increasing content of acetonitrile in the mobile phase, and the maximum $R_{\mathrm{S}}$ was observed at an $\mathrm{ACN} / \mathrm{H}_{2} \mathrm{O}$ ratio of $90 / 10$. Comparing the chiral separation results obtained from normal-phase and reverse-phase HPLC, the normal-phase HPLC presented better separation efficiency for etoxazole enantiomers than reverse-phase HPLC.

Table 1. Enantiomeric separation of etoxazole enantiomers on four chiral columns.

\begin{tabular}{|c|c|c|c|c|c|c|c|c|c|c|c|c|}
\hline Column & Mobile Phase & $\operatorname{Ratio}(v / v)$ & $k_{1}$ & $k_{2}$ & $\alpha$ & $R_{\mathrm{s}}$ & Mobile Phase & Ratio (v/v) & $k_{1}$ & $k_{2}$ & $\alpha$ & $R_{\mathrm{s}}$ \\
\hline \multirow{7}{*}{$\begin{array}{c}\text { Lux } \\
\text { Cellulose-1 }\end{array}$} & \multirow{4}{*}{ HEX/IPA } & $98 / 2$ & 1.81 & 3.04 & 1.68 & 4.50 & \multirow{4}{*}{$\mathrm{MEOH} / \mathrm{H}_{2} \mathrm{O}$} & $100 / 0$ & 0.40 & 0.46 & 1.14 & 0.54 \\
\hline & & $95 / 5$ & 0.97 & 1.63 & 1.68 & 3.39 & & $95 / 5$ & 0.68 & 1.10 & 1.60 & 2.03 \\
\hline & & $90 / 10$ & 0.71 & 1.01 & 1.42 & 2.70 & & $90 / 10$ & 1.02 & 1.82 & 1.79 & 2.43 \\
\hline & & $80 / 20$ & 0.51 & 0.64 & 1.26 & 1.47 & & & & & & \\
\hline & \multirow{3}{*}{$\mathrm{HEX} / \mathrm{BuOH}$} & $98 / 2$ & 1.79 & 2.41 & 1.34 & 2.46 & \multirow{3}{*}{$\mathrm{ACN} / \mathrm{H}_{2} \mathrm{O}$} & $90 / 10$ & 0.37 & 0.95 & 2.54 & 3.94 \\
\hline & & $95 / 5$ & 1.07 & 1.31 & 1.22 & 1.98 & & $80 / 20$ & 0.55 & 1.40 & 2.53 & 3.62 \\
\hline & & $80 / 20$ & 0.44 & 0.50 & 1.15 & 0.82 & & & & & & \\
\hline \multirow{6}{*}{$\begin{array}{c}\text { Lux } \\
\text { Cellulose-3 }\end{array}$} & \multirow{4}{*}{ HEX/IPA } & $98 / 2$ & 2.17 & 3.52 & 1.62 & 3.14 & \multirow{4}{*}{$\mathrm{MEOH} / \mathrm{H}_{2} \mathrm{O}$} & $95 / 5$ & I & I & 1 & / \\
\hline & & $95 / 5$ & 1.15 & 1.64 & 1.43 & 2.02 & & $90 / 10$ & l & / & / & / \\
\hline & & $90 / 10$ & 0.69 & 0.91 & 1.33 & 1.22 & & $85 / 15$ & I & I & / & I \\
\hline & & $85 / 15$ & 0.50 & 0.64 & 1.29 & 0.93 & & $80 / 20$ & I & I & / & I \\
\hline & \multirow{2}{*}{$\mathrm{HEX} / \mathrm{BuOH}$} & $85 / 15$ & 0.31 & 0.59 & 1.92 & 0.90 & \multirow{2}{*}{$\mathrm{ACN} / \mathrm{H}_{2} \mathrm{O}$} & $60 / 40$ & 0.50 & 1.54 & 3.09 & 6.30 \\
\hline & & $80 / 20$ & 0.25 & 0.48 & 1.91 & 0.82 & & & & & & \\
\hline \multirow{10}{*}{ Chiralpak IC } & \multirow{5}{*}{ HEX/IPA } & $90 / 10$ & 1.02 & 4.98 & 4.87 & 13.21 & \multirow{5}{*}{$\mathrm{MEOH} / \mathrm{H}_{2} \mathrm{O}$} & $100 / 0$ & 0.18 & 0.34 & 1.84 & 2.34 \\
\hline & & $85 / 15$ & 0.81 & 3.58 & 4.40 & 12.91 & & $95 / 5$ & 0.33 & 0.64 & 1.94 & 3.36 \\
\hline & & $80 / 20$ & 0.65 & 2.79 & 4.28 & 12.35 & & $90 / 10$ & 0.52 & 1.02 & 1.99 & 4.35 \\
\hline & & $75 / 25$ & 0.54 & 2.30 & 4.23 & 11.55 & & $85 / 15$ & 0.80 & 1.64 & 2.06 & 5.26 \\
\hline & & $70 / 30$ & 0.52 & 2.06 & 3.93 & 11.14 & & $80 / 20$ & 1.17 & 2.47 & 2.11 & 5.84 \\
\hline & \multirow{5}{*}{$\mathrm{HEX} / \mathrm{BuOH}$} & $95 / 5$ & 1.26 & 4.16 & 3.31 & 14.98 & \multirow{5}{*}{$\mathrm{ACN} / \mathrm{H}_{2} \mathrm{O}$} & $90 / 10$ & 0.17 & 0.56 & 3.36 & 4.82 \\
\hline & & $90 / 10$ & 0.79 & 3.45 & 4.38 & 13.85 & & $80 / 20$ & 0.39 & 1.15 & 2.94 & 5.40 \\
\hline & & $85 / 15$ & 0.60 & 2.40 & 4.00 & 12.97 & & $70 / 30$ & 0.84 & 2.31 & 2.74 & 6.89 \\
\hline & & $80 / 20$ & 0.48 & 1.80 & 3.79 & 9.33 & & $60 / 40$ & 1.89 & 4.98 & 2.64 & 9.40 \\
\hline & & $75 / 25$ & 0.40 & 1.44 & 3.65 & 8.30 & & & & & & \\
\hline \multirow{3}{*}{$\begin{array}{c}\text { Chiralpak } \\
\text { AD }\end{array}$} & \multirow[t]{3}{*}{$\mathrm{HEX} / \mathrm{BuOH}$} & $90 / 10$ & 1.27 & 2.83 & 2.22 & 7.57 & \multirow[t]{3}{*}{$\mathrm{ACN} / \mathrm{H}_{2} \mathrm{O}$} & $70 / 30$ & 0.68 & 0.86 & 1.26 & 0.93 \\
\hline & & $85 / 15$ & 0.90 & 2.04 & 2.26 & 7.32 & & $60 / 40$ & 1.14 & 1.43 & 1.25 & 1.02 \\
\hline & & $80 / 20$ & 0.74 & 1.66 & 2.24 & 6.83 & & & & & & \\
\hline
\end{tabular}

\subsection{Effects of Temperature on Etoxazole Separation}

Column temperature is an important parameter for chiral separation and contributes to revealing the chiral recognition mechanism. In this study, the effects of temperature on etoxazole enantiomeric separation were carefully studied from $10^{\circ} \mathrm{C}$ to $40^{\circ} \mathrm{C}$ on Lux Cellulose-1, Lux Cellulose-3, Chiralpak IC, and Chiralpak AD columns under normal-phase and reverse-phase conditions, respectively (Figure 2). Table S1 lists the separation resolution and chromatographic condition changes with temperature. Etoxazole enantiomers were separated on Lux Cellulose-1 (HEX/IPA = 85/15 and HEX/BuOH = 85/15), Lux Cellulose-3 (HEX/IPA = 90/10 and HEX/BuOH =95/5), Chiralpak IC (HEX/IPA = 70/30 and $\mathrm{HEX} / \mathrm{BuOH}=60 / 40)$, and Chiralpak AD $(\mathrm{HEX} / \mathrm{IPA}=50 / 50$ and $\mathrm{HEX} / \mathrm{BuOH}=60 / 40)$ columns under normal-phase HPLC conditions. As for reverse-phase HPLC, etoxazole enantiomers were separated on Lux Cellulose-1 (MEOH/ $\mathrm{H}_{2} \mathrm{O}=95 / 5$ and $\left.\mathrm{ACN} / \mathrm{H}_{2} \mathrm{O}=80 / 20\right)$, Lux Cellulose-3 $\left(\mathrm{MEOH} / \mathrm{H}_{2} \mathrm{O}=90 / 10\right.$ and $\left.\mathrm{ACN} / \mathrm{H}_{2} \mathrm{O}=70 / 30\right)$, Chiralpak IC $\left(\mathrm{MEOH} / \mathrm{H}_{2} \mathrm{O}=90 / 10\right.$ and $\left.\mathrm{ACN} / \mathrm{H}_{2} \mathrm{O}=80 / 20\right)$, and Chiralpak AD $\left(\mathrm{MEOH} / \mathrm{H}_{2} \mathrm{O}=90 / 10\right.$ and $\left.\mathrm{ACN} / \mathrm{H}_{2} \mathrm{O}=60 / 40\right)$ columns, in terms of separation resolution and retention time. The results indicated that temperature had a significant effect on the interaction between etoxazole 
enantiomers and different chiral stationary phases under both reverse-phase and normal-phase HPLC. Generally, lower temperature often results in better resolution, longer retention time, and wider peaks. In accordance with this phenomenon, the $k_{1}, k_{2}$, and $R_{\mathrm{s}}$ of etoxazole enantiomers decreased with increasing temperature on four chiral columns regardless of whether reverse-phase or normal-phase HPLC was used for separation. For instance, the $k_{1}, k_{2}$, and $R_{\mathrm{S}}$ decreased from 0.53 to $0.41,2.70$ to 1.23 , and 11.29 to 8.15 on Chiralpak IC with HEX/IPA ratio of 70/30 under normal-phase conditions. Likewise, the $k_{1}, k_{2}$, and $R_{\mathrm{S}}$ decreased from 0.59 to $0.42,1.22$ to 0.79 , and 4.91 to 3.91 on Chiralpak IC with $\mathrm{MEOH} / \mathrm{H}_{2} \mathrm{O}$ ratio of 90/10 in reverse-phase HPLC. However, temperature sometimes has little effect on chiral separation. For instance, the chiral separation of etoxazole enantiomers on Chiralpak AD with $\mathrm{MEOH} / \mathrm{H}_{2} \mathrm{O}$ ratio of $90 / 10$ showed that the maximum $R_{\mathrm{S}}=1.14$ was obtained at $40^{\circ} \mathrm{C}$.
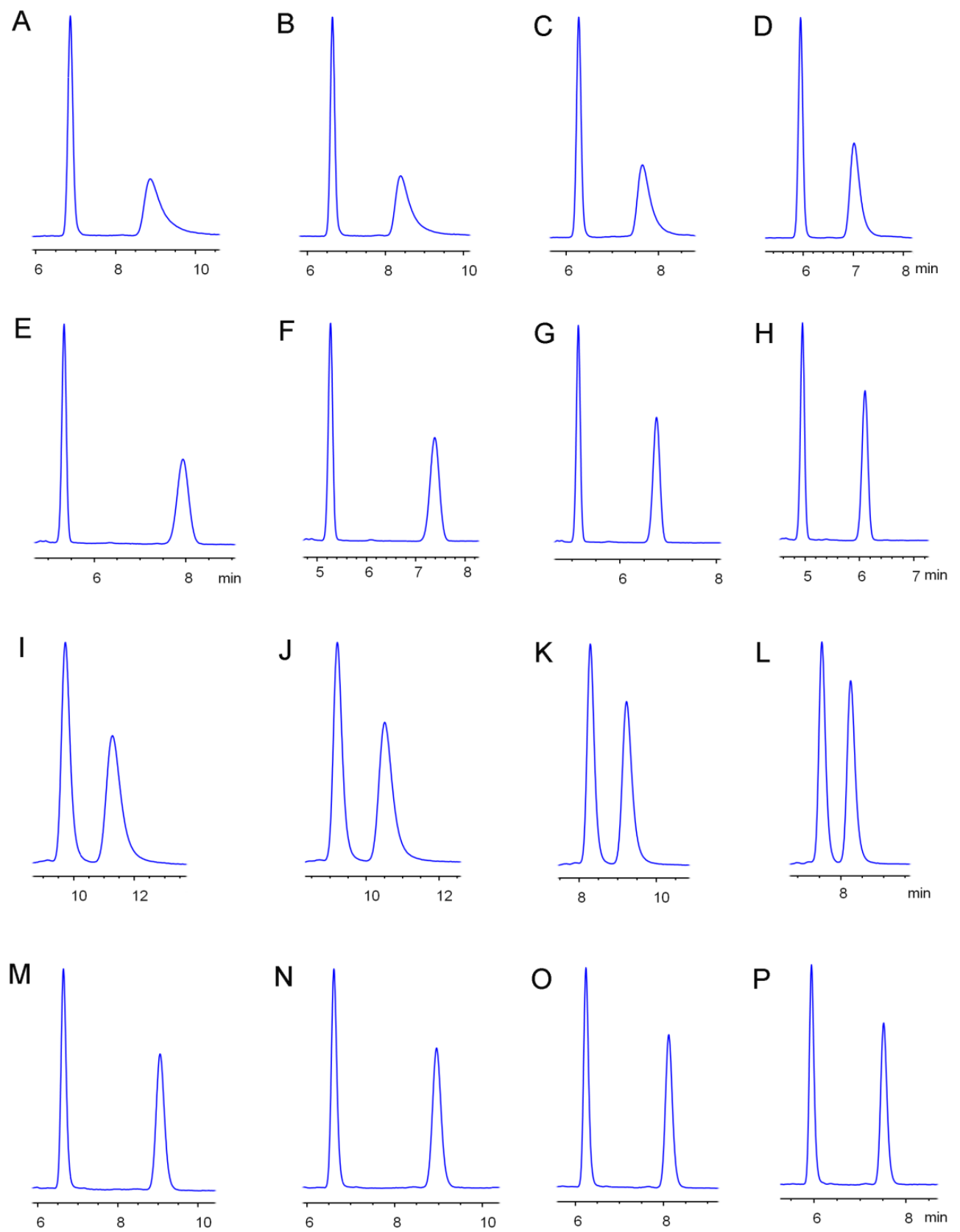

Figure 2. The effects of temperature on etoxazole enantiomeric separation with Lux cellulose-1 $\left(\mathrm{MEOH} / \mathrm{H}_{2} \mathrm{O}=85 / 15,\left(\right.\right.$ A) $10{ }^{\circ} \mathrm{C}$, (B) $20^{\circ} \mathrm{C}$, (C) $30{ }^{\circ} \mathrm{C}$, (D) $\left.40{ }^{\circ} \mathrm{C}\right)$, Lux cellulose-3 $\left(\mathrm{ACN} / \mathrm{H}_{2} \mathrm{O}=70 / 30\right.$, (E) $\left.10^{\circ} \mathrm{C},(\mathbf{F}) 20^{\circ} \mathrm{C},(\mathbf{G}) 30^{\circ} \mathrm{C}, \mathrm{H} 40^{\circ} \mathrm{C}\right)$, Chiralpak IC (MEOH/ $\mathrm{H}_{2} \mathrm{O}=90 / 10,(\mathrm{I}) 10^{\circ} \mathrm{C},(\mathrm{J}) 20^{\circ} \mathrm{C},(\mathbf{K}) 30^{\circ} \mathrm{C}$, (L) $\left.40^{\circ} \mathrm{C}\right)$, and Chiralpak $\mathrm{AD}\left(\mathrm{ACN} / \mathrm{H}_{2} \mathrm{O}=60 / 40,(\mathbf{M}) 10^{\circ} \mathrm{C},(\mathbf{N}) 20^{\circ} \mathrm{C},(\mathbf{O}) 30^{\circ} \mathrm{C},(\mathbf{P}) 40^{\circ} \mathrm{C}\right)$ columns. 


\subsection{Thermodynamic Parameters}

In order to reveal the thermodynamic driving forces involved in etoxazole enantiomer separation, the van 't Hoff equation was applied to calculate the thermodynamic parameters, such as enthalpy $(\Delta H)$ and entropy $(\Delta S)$ based on the retention factor $\left(k_{1}, k_{2}\right)$ and selectivity $(\alpha)$ obtained from Lux Cellulose-1, Lux Cellulose-3, Chiralpak IC, and Chiralpak AD columns under different temperatures (Figure 3). Table 2 summarizes the thermodynamic parameters of etoxazole enantiomers on four chiral columns under normal-phase and reverse-phase conditions, which indicated that good linearity was obtained in linear regression of $\operatorname{lnk}$ versus $1 / T$ and $\ln \alpha$ versus $1 / T$ with all the coefficients of determination $\left(R^{2}\right)$ over 0.896 . The $\Delta H$ values of etoxazole enantiomers on four chiral columns under normal-phase HPLC ranged from $-1.91 \mathrm{KJ} / \mathrm{mol}$ to $-24.53 \mathrm{KJ} / \mathrm{mol}$ when HEX/IPA and $\mathrm{HEX} / \mathrm{BuOH}$ were used as the mobile phase. Likewise, the $\Delta \mathrm{H}$ values of etoxazole enantiomers on the four chiral columns under reverse-phase HPLC ranged from $-6.24 \mathrm{KJ} / \mathrm{mol}$ to $-15.02 \mathrm{KJ} / \mathrm{mol}$ when $\mathrm{MEOH} / \mathrm{H}_{2} \mathrm{O}$ and $\mathrm{ACN} / \mathrm{H}_{2} \mathrm{O}$ were used as the mobile phase. The negative value of $\Delta H$ indicated the process of etoxazole enantiomer transfer from the mobile phase to different CSPs was mainly driven by enthalpy under normal-phase and reverse-phase HPLC. $\Delta \Delta H$ and $\Delta \Delta S$ values were ranged from $-1.82 \mathrm{KJ} / \mathrm{mol}$ to $-12.70 \mathrm{KJ} / \mathrm{mol}$ and from $-1.15 \mathrm{~J} / \mathrm{mol}$ to $-31.25 \mathrm{~J} / \mathrm{mol}$ on the four chiral columns under normal-phase and reverse-phase HPLC, respectively. The negative $\Delta \Delta H$ implied the lower temperature could lead to better resolution, which was clarified in temperature study. Moreover, the negative values of $\Delta \Delta H$ also implied that the $\Delta H$ of the second enantiomer was more negative than the first eluted enantiomer, which indicated the CSPs have stronger interaction with the second eluted enantiomer than the first one. Hydrogen bonding, $\pi-\pi$ interaction, and dipole-dipole interaction were the main forces in chiral separation according to previous study $[17,33]$. Good linearity of $\ln \alpha$ versus $1 / T$ implied the main forces involved in etoxazole enantiomers separation. Similarly, poor linearity indicated multiple interaction forces exist in enantiomers separation [34,35]. For instance, the linear regression of $\ln \alpha$ versus $1 / T$ of lambda-cyhalothrin enantiomers on the Lux Cellulose- 3 column is 0.623 with an $\mathrm{ACN} / \mathrm{H}_{2} \mathrm{O}$ ratio of 60/40, which implies that multiple interaction forces exist between lambda-cyhalothrin enantiomers and CSP [35].
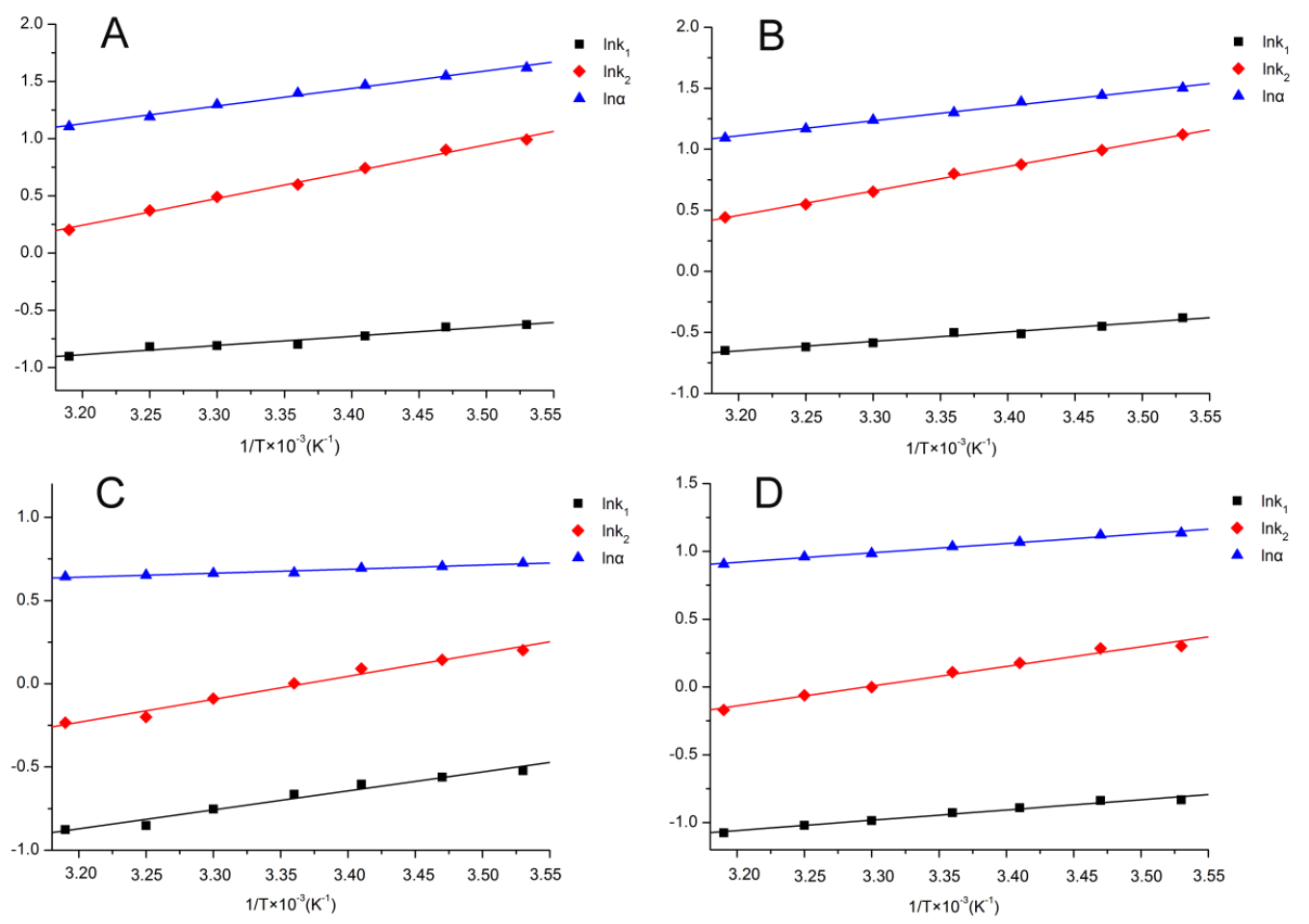

Figure 3. Van't Hoff plots of etoxazole on Chirapak IC chiral column ((A) HEX/IPA = 70/30, (B) $\mathrm{HEX} / \mathrm{BuOH}=60 / 40$, (C) $\mathrm{MEOH} / \mathrm{H}_{2} \mathrm{O}=90 / 10$, and (D) $\mathrm{ACN} / \mathrm{H}_{2} \mathrm{O}=80 / 20$ ). 
Table 2. Van't Hoff equations and thermodynamic parameters of etoxazole enantiomers with four chiral columns.

\begin{tabular}{|c|c|c|c|c|c|c|c|c|c|}
\hline Column & Mobile Phase & $\ln k=-\Delta H / R T+\Delta S / R+\ln \varphi$ & $R^{2}$ & $\Delta H\left(\mathrm{KJ} \mathrm{mol}^{-1}\right)$ & $\Delta S / R+\ln \varphi$ & $\ln \alpha=-\Delta \Delta H / R T+\Delta \Delta \mathrm{S} / \mathrm{R}$ & $R^{2}$ & $\Delta \Delta H\left(\mathrm{KJ} \mathrm{mol}^{-1}\right)$ & $\Delta \Delta S\left(\mathrm{~J} \mathrm{~mol}^{-1}\right)$ \\
\hline \multirow{4}{*}{ Lux Cellulose-1 } & HEX/IPA (85/15) & $\begin{array}{l}\ln k_{1}=857.92 / T-2.8677 \\
\ln k_{2}=1446.1 / T-4.4031\end{array}$ & $\begin{array}{l}0.989 \\
0.995 \\
\end{array}$ & $\begin{array}{l}-7.13 \\
-12.02 \\
\end{array}$ & $\begin{array}{l}-2.87 \\
-4.78 \\
\end{array}$ & $\ln \alpha=588.19 / T-1.5353$ & 0.999 & -4.89 & -12.77 \\
\hline & HEX/BuOH (60/40) & $\begin{array}{l}\ln k_{1}=229.88 / T-0.7073 \\
\ln k_{2}=1225.7 / T-3.8741\end{array}$ & $\begin{array}{l}0.896 \\
0.995\end{array}$ & $\begin{array}{l}-1.91 \\
-10.19\end{array}$ & $\begin{array}{l}-0.71 \\
-3.87\end{array}$ & $\ln \alpha=995.79 / T-3.1668$ & 0.988 & -8.28 & -26.33 \\
\hline & $\mathrm{MEOH} / \mathrm{H}_{2} \mathrm{O}(95 / 5)$ & $\begin{array}{l}\ln k_{1}=963.97 / T-3.6775 \\
\ln k_{2}=1303.9 / T-4.3444\end{array}$ & $\begin{array}{l}0.964 \\
0.970\end{array}$ & $\begin{array}{l}-8.01 \\
-10.84\end{array}$ & $\begin{array}{l}-3.68 \\
-4.34\end{array}$ & $\ln \alpha=339.91 / T-0.6669$ & 0.984 & -2.83 & -5.54 \\
\hline & $\mathrm{ACN} / \mathrm{H}_{2} \mathrm{O}(80 / 20)$ & $\begin{array}{l}\ln k_{1}=927.83 / T-3.7497 \\
\ln k_{2}=1617.5 / T-5.1432\end{array}$ & $\begin{array}{l}0.935 \\
0.946\end{array}$ & $\begin{array}{l}-7.71 \\
-13.45\end{array}$ & $\begin{array}{l}-3.75 \\
-5.14 \\
\end{array}$ & $\ln \alpha=689.72 / T-1.3936$ & 0.960 & -5.73 & -11.59 \\
\hline \multirow{4}{*}{ Lux Cellulose-3 } & HEX/IPA (90/10) & $\begin{array}{l}\ln k_{1}=2496.5 / T-7.9557 \\
\ln k_{2}=2950.1 / T-9.0828\end{array}$ & $\begin{array}{l}0.978 \\
0.981\end{array}$ & $\begin{array}{l}-20.76 \\
-24.53\end{array}$ & $\begin{array}{l}-7.96 \\
-9.08\end{array}$ & $\ln \alpha=453.68 / T-1.1271$ & 0.985 & -3.77 & -9.37 \\
\hline & HEX/BuOH (95/5) & $\begin{array}{l}\ln k_{1}=1596.1 / T-5.8905 \\
\ln k_{2}=2635.7 / T-8.929\end{array}$ & $\begin{array}{l}0.995 \\
0.995\end{array}$ & $\begin{array}{l}-13.27 \\
-21.91\end{array}$ & $\begin{array}{l}-5.89 \\
-8.93 \\
\end{array}$ & $\ln \alpha=1039.6 / T-3.0384$ & 0.995 & -8.64 & -25.26 \\
\hline & $\mathrm{MEOH} / \mathrm{H}_{2} \mathrm{O}(90 / 10)$ & $\begin{array}{l}1 \\
1\end{array}$ & $\begin{array}{l}1 \\
1\end{array}$ & $\begin{array}{l}1 \\
1\end{array}$ & $\begin{array}{l}1 \\
1\end{array}$ & 1 & 1 & 1 & 1 \\
\hline & $\mathrm{ACN} / \mathrm{H}_{2} \mathrm{O}(70 / 30)$ & $\begin{array}{l}\ln k_{1}=836 / T-4.1678 \\
\ln k_{2}=1806.7 / T-6.4262\end{array}$ & $\begin{array}{l}0.928 \\
0.975\end{array}$ & $\begin{array}{l}-6.95 \\
-15.02\end{array}$ & $\begin{array}{l}-4.17 \\
-6.43\end{array}$ & $\ln \alpha=970.74 / T-2.2584$ & 0.996 & -8.07 & -18.78 \\
\hline \multirow{4}{*}{ Chiralpak IC } & HEX/IPA (70/30) & $\begin{array}{l}\ln k_{1}=799.27 / T-3.4457 \\
\ln k_{2}=2327.3 / T-7.2041\end{array}$ & $\begin{array}{l}0.950 \\
0.994 \\
\end{array}$ & $\begin{array}{l}-6.65 \\
-19.35 \\
\end{array}$ & $\begin{array}{l}-3.45 \\
-7.20 \\
\end{array}$ & $\ln \alpha=1528.1 / T-3.7584$ & 0.991 & -12.70 & -31.25 \\
\hline & $\mathrm{HEX/BuOH} \mathrm{(60/40)}$ & $\begin{array}{l}\ln k_{1}=771.56 / T-3.1208 \\
\ln k_{2}=1988.7 / T-5.9052\end{array}$ & $\begin{array}{l}0.964 \\
0.997\end{array}$ & $\begin{array}{l}-6.41 \\
-16.53\end{array}$ & $\begin{array}{l}-3.12 \\
-5.91\end{array}$ & $\ln \alpha=1217.1 / T-2.7845$ & 0.995 & -10.12 & -23.15 \\
\hline & $\mathrm{MEOH} / \mathrm{H}_{2} \mathrm{O}(90 / 10)$ & $\begin{array}{l}\ln k_{1}=1130.8 / T-4.4897 \\
\ln k_{2}=1373.9 / T-4.628\end{array}$ & $\begin{array}{l}0.969 \\
0.983\end{array}$ & $\begin{array}{l}-9.40 \\
-11.42\end{array}$ & $\begin{array}{l}-4.49 \\
-4.63\end{array}$ & $\ln \alpha=243.06 / T-0.1384$ & 0.969 & -2.02 & -1.15 \\
\hline & $\mathrm{ACN} / \mathrm{H}_{2} \mathrm{O}(80 / 20)$ & $\begin{array}{l}\ln k_{1}=750.13 / T-3.4584 \\
\ln k_{2}=1439.8 / T-4.7455\end{array}$ & $\begin{array}{l}0.973 \\
0.980\end{array}$ & $\begin{array}{l}-6.24 \\
-11.97\end{array}$ & $\begin{array}{l}-3.46 \\
-4.75\end{array}$ & $\ln \alpha=689.69 / T-1.2872$ & 0.985 & -5.73 & -10.70 \\
\hline \multirow{4}{*}{ Chiralpak AD } & HEX/IPA (50/50) & $\begin{array}{l}\ln k_{1}=968.4 / T-3.3552 \\
\ln k_{2}=2302.5 / T-6.9441\end{array}$ & $\begin{array}{l}0.992 \\
0.990\end{array}$ & $\begin{array}{l}-8.05 \\
-19.14\end{array}$ & $\begin{array}{l}-3.36 \\
-6.94 \\
\end{array}$ & $\ln \alpha=1334.1 / T-3.1136$ & 0.990 & -11.09 & -25.89 \\
\hline & HEX/BuOH (60/40) & $\begin{array}{l}\ln k_{1}=1225.2 / T-3.3552 \\
\ln k_{2}=1976.5 / T-5.1478\end{array}$ & $\begin{array}{l}0.992 \\
0.993\end{array}$ & $\begin{array}{l}-10.19 \\
-16.43\end{array}$ & $\begin{array}{l}-3.36 \\
-5.15 \\
\end{array}$ & $\ln \alpha=751.25 / T-1.7925$ & 0.987 & -6.25 & -14.90 \\
\hline & $\mathrm{MEOH} / \mathrm{H}_{2} \mathrm{O}(90 / 10)$ & $\begin{array}{l}\ln k_{1}=1335.6 / T-5.0511 \\
\ln k_{2}=1597 / T-5.5215\end{array}$ & $\begin{array}{l}0.966 \\
0.970\end{array}$ & $\begin{array}{l}-11.10 \\
-13.28\end{array}$ & $\begin{array}{l}-5.05 \\
-5.52\end{array}$ & $\ln \alpha=261.34 / T-0.4704$ & 0.972 & -2.17 & -3.91 \\
\hline & $\mathrm{ACN} / \mathrm{H}_{2} \mathrm{O}(60 / 40)$ & $\begin{array}{l}\ln k_{1}=1380.7 / T-4.5931 \\
\ln k_{2}=1599.7 / T-5.1111\end{array}$ & $\begin{array}{l}0.966 \\
0.969\end{array}$ & $\begin{array}{l}-11.48 \\
-13.30 \\
\end{array}$ & $\begin{array}{l}-4.59 \\
-5.11 \\
\end{array}$ & $\ln \alpha=219.06 / T-0.518$ & 0.985 & -1.82 & -4.31 \\
\hline
\end{tabular}

/ represents no data. 


\subsection{Elution Order of Etoxazole Enantiomers on Different Chiral Columns}

In the present study, small-scale enantiopure $R$-etoxazole and $S$-etoxazole were prepared by HPLC using a Chiralpak-AD column under normal-phase conditions. After that, the enantiopure enantiomers were injected into normal-phase and reverse-phase HPLC with different chiral columns to confirm the elution order (Figure 4). According to the absolute configuration and elution order of etoxazole enantiomers confirmed by a previous study [10,13,31], the first eluted enantiomer on the Chiralpak AD column was S-etoxazole, while the first eluted enantiomer on Lux Cellulose-1, Lux Cellulose-3, and Chiralpak IC columns was $R$-etoxazole. Furthermore, the elution order of etoxazole enantiomers on the same chiral column is identical no matter which of HEX/IPA, HEX/BuOH, $\mathrm{MEOH} / \mathrm{H}_{2} \mathrm{O}$, or $\mathrm{ACN} / \mathrm{H}_{2} \mathrm{O}$ was used as the mobile phase.
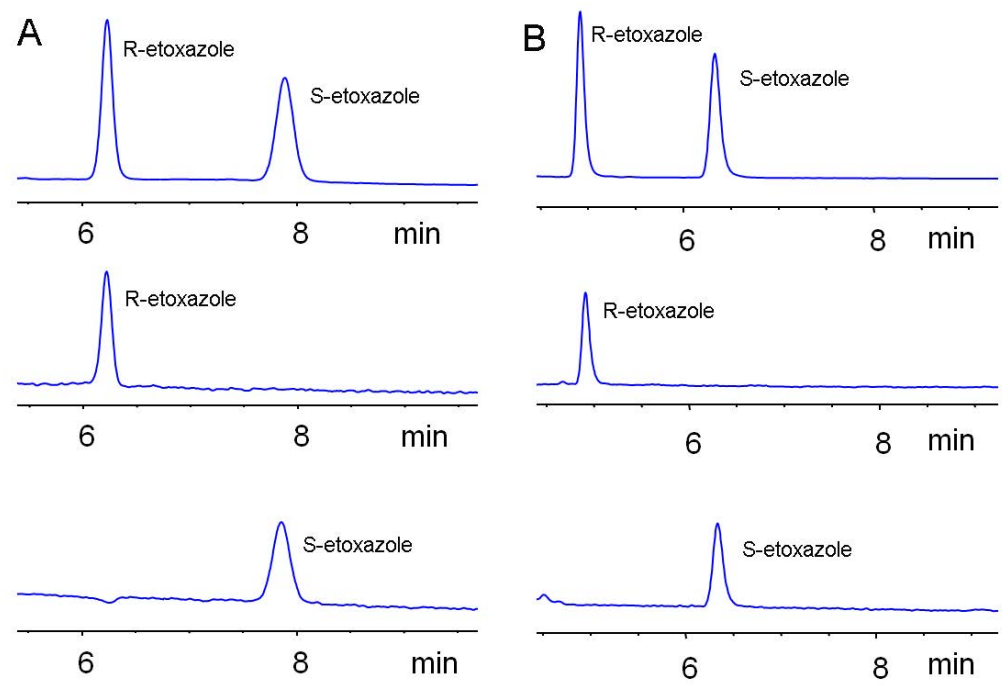

Figure 4. Eluted order of etoxazole enantiomers on (A) Lux Cellulose-3 column (acetonitrile/water, 70/30) and (B) Chirapak IC (acetonitrile/water, 80/20).

\subsection{Etoxazole Enantiomers Analysis in Vegetables}

Based on baseline separation of etoxazole enantiomers under normal-phase and reverse-phase HPLC, the quantitative analysis of etoxazole enantiomers was validated in cabbage, tomato, cucumber, and soil. The solvent and matrix-matched calibration curves were obtained from the concentration range of $0.05-10 \mathrm{mg} / \mathrm{L}$ for $R$-etoxazole and S-etoxazole, respectively. Linear regression demonstrated that good linearity was obtained with coefficient of determination $\left(R^{2}\right)$ values all over 0.998 (Table S2). The matrix effect was investigated in cucumber, cabbage, tomato, and soil samples, and the slope ratios in different sample matrices were 0.93 to 1.01, and the absolute values of the matrix effect were $0.73 \%$ to $6.84 \%$. Generally, it may be neglected when matrix effect value is between $-10 \%$ and $10 \%$. The matrix effect could be neglected in this study. The recovery and relative standard deviation (RSD) were employed to assess the accuracy and precision of the residue analytical method based on three spiked levels with five replicates in different matrices (Table 3). The interday precision (RSD) was used to evaluate the reproducibility of the developed method, which ranged from 2.92 to 6.64. The intraday recoveries ranged from 80.27 to 102.66 , and intraday precision ranged from 0.62 to 8.02 for etoxazole enantiomers in cucumber, tomato, cabbage, and soil. The LOD was $0.015 \mathrm{mg} / \mathrm{kg}$ and the corresponding LOQ was $0.05 \mathrm{mg} / \mathrm{kg}$. Such results indicated that the developed method was reliable and effective for the residue analysis of etoxazole enantiomers in vegetables. 
Table 3. Recovery and relative standard deviation (RSD) for etoxazole enantiomers among different matrixes for three spiked levels $(n=15)$.

\begin{tabular}{|c|c|c|c|c|c|c|c|c|c|c|}
\hline \multirow{3}{*}{ Compound } & \multirow{3}{*}{ Matrix } & \multirow{3}{*}{$\begin{array}{l}\text { Spiked Levels } \\
\left(\mathrm{mg} \mathrm{kg}^{-1}\right)\end{array}$} & \multicolumn{6}{|c|}{ Intraday } & \multirow{2}{*}{\multicolumn{2}{|c|}{ Interday }} \\
\hline & & & \multicolumn{2}{|c|}{ Day 1} & \multicolumn{2}{|c|}{ Day 2} & \multicolumn{2}{|c|}{ Day 3} & & \\
\hline & & & $\begin{array}{c}\text { Recovery } \\
(\%)\end{array}$ & $\begin{array}{c}\mathrm{RSD} \\
(\%)\end{array}$ & $\begin{array}{c}\text { Recovery } \\
(\%)\end{array}$ & $\begin{array}{l}\text { RSD } \\
(\%)\end{array}$ & $\begin{array}{l}\text { Recovery } \\
(\%)\end{array}$ & $\begin{array}{l}\text { RSD } \\
(\%)\end{array}$ & $\begin{array}{c}\text { Recovery } \\
(\%)\end{array}$ & $\begin{array}{c}\text { RSD } \\
(\%)\end{array}$ \\
\hline \multirow{12}{*}{$R$-etoxazole } & \multirow{3}{*}{ Soil } & 0.05 & 84.46 & 5.61 & 84.19 & 5.36 & 89.48 & 6.84 & 86.04 & 6.64 \\
\hline & & 0.5 & 94.45 & 5.15 & 94.05 & 2.57 & 93.99 & 3.30 & 94.16 & 3.84 \\
\hline & & 5 & 97.46 & 5.80 & 97.34 & 1.80 & 99.58 & 4.48 & 98.13 & 4.48 \\
\hline & \multirow{3}{*}{ Cucumber } & 0.05 & 92.33 & 2.51 & 91.02 & 5.53 & 89.56 & 8.02 & 90.97 & 5.89 \\
\hline & & 0.5 & 102.66 & 1.30 & 97.30 & 3.25 & 90.99 & 1.47 & 96.98 & 5.39 \\
\hline & & 5 & 98.45 & 1.41 & 96.02 & 3.63 & 93.32 & 1.23 & 95.93 & 3.22 \\
\hline & \multirow{3}{*}{ Cabbage } & 0.05 & 82.75 & 5.00 & 83.80 & 3.28 & 86.71 & 7.31 & 84.42 & 5.85 \\
\hline & & 0.5 & 91.99 & 4.03 & 95.04 & 3.23 & 92.02 & 3.23 & 93.02 & 3.83 \\
\hline & & 5 & 95.88 & 2.71 & 97.44 & 2.18 & 94.84 & 3.15 & 96.06 & 2.92 \\
\hline & \multirow{3}{*}{ Tomato } & 0.05 & 82.71 & 4.33 & 82.56 & 6.31 & 84.59 & 6.63 & 83.29 & 5.96 \\
\hline & & 0.5 & 92.27 & 3.36 & 89.42 & 2.02 & 94.85 & 4.08 & 92.18 & 4.09 \\
\hline & & 5 & 91.69 & 0.62 & 96.02 & 3.98 & 92.22 & 4.23 & 93.31 & 3.98 \\
\hline \multirow{12}{*}{ S-etoxazole } & \multirow{3}{*}{ Soil } & 0.05 & 85.82 & 5.80 & 88.94 & 4.78 & 87.64 & 4.58 & 87.47 & 5.28 \\
\hline & & 0.5 & 94.11 & 2.45 & 96.03 & 4.31 & 94.88 & 4.38 & 95.01 & 3.92 \\
\hline & & 5 & 99.48 & 5.45 & 94.91 & 5.80 & 97.59 & 3.73 & 97.33 & 5.42 \\
\hline & \multirow{3}{*}{ Cucumber } & 0.05 & 90.16 & 4.84 & 89.59 & 5.91 & 87.54 & 3.92 & 89.09 & 5.13 \\
\hline & & 0.5 & 100.69 & 1.38 & 94.50 & 2.13 & 94.12 & 4.14 & 96.44 & 4.16 \\
\hline & & 5 & 96.12 & 3.69 & 94.96 & 3.35 & 91.75 & 1.77 & 94.28 & 3.65 \\
\hline & \multirow{3}{*}{ Cabbage } & 0.05 & 80.41 & 5.03 & 87.29 & 3.60 & 87.72 & 4.97 & 85.14 & 6.02 \\
\hline & & 0.5 & 94.22 & 4.28 & 94.14 & 3.80 & 89.89 & 3.14 & 92.75 & 4.37 \\
\hline & & 5 & 97.27 & 6.07 & 98.65 & 3.38 & 96.89 & 3.49 & 97.61 & 4.55 \\
\hline & \multirow{3}{*}{ Tomato } & 0.05 & 80.27 & 3.14 & 83.52 & 5.66 & 88.19 & 6.26 & 84.00 & 6.55 \\
\hline & & 0.5 & 91.21 & 3.02 & 93.16 & 2.23 & 95.13 & 5.25 & 93.17 & 4.14 \\
\hline & & 5 & 92.01 & 1.62 & 97.17 & 4.62 & 95.30 & 4.82 & 94.83 & 4.60 \\
\hline
\end{tabular}

\section{Materials and Methods}

\subsection{Chemicals and Reagents}

Etoxazole (purity $=98.0 \%$ ) was purchased from J\&K Scientific (Beijing, China). Methanol (MEOH), acetonitrile (ACN), and hexane (HEX) were HPLC-grade and bought from Spectrum Chemical (Shanghai, China). Isopropanol (IPA), $n$-butanol (BuOH), ethyl acetate, sodium chloride, anhydrous sodium sulfate, and other chemicals were analytical grade and purchased from Aladdin Reagents Co., Ltd. (Shanghai, China). Ultrapure water $\left(\mathrm{H}_{2} \mathrm{O}\right)$ was purified using a Milli-Q system (Billerica, MA, USA).

\subsection{Apparatus and Chromatographic Conditions}

Normal-phase chiral HPLC analysis was performed on a Shimadzu Prominence HPLC system (Kyoto, Japan), which equipped with a DGU-20A degasser, two LC-20AD pumps, SIL-20AD automated sample injector, CTO-20A column oven, SPD-20A photodiode array (PDA) detector. Data were collected and processed by the Shimadzu LabSolutions Ver.5.6 (Shimadzu, Kyoto, Japan). Reverse-phase chiral HPLC analysis was performed on an Agilent 1260 system (Agilent, Santa Clara, CA, USA), equipped with a G1322A degasser, G1311B quatpump, G1329B autosampler, G1316A column compartment and G1315D diode array detector. The signal was acquired and processed by an Agilent Chemstation Ver.B.04 (Agilent, Santa Clara, CA, USA). Etoxazole enantiomers were separated on four chiral columns under normal-phase and reverse-phase conditions, including Lux Cellulose-1 [cellulose-tris-(3,5-dimethylphenylcarbamate), $250 \mathrm{~mm} \times 4.6 \mathrm{~mm}$ (i.d.), $5 \mu \mathrm{m}$ ], Lux Cellulose-3 [cellulose-tris-(4-methylbenzoate), $250 \mathrm{~mm} \times 4.6 \mathrm{~mm}$ (i.d.), $5 \mu \mathrm{m}$ ], Chiralpak IC [cellulose tris-(3,5-dichlophenylcarbamate), $250 \mathrm{~mm} \times 4.6 \mathrm{~mm}$ (i.d.), $5 \mu \mathrm{m}$ ], and Chiralpak AD [amylose-tris-(3,5-dimethylphenylcarbamate), $250 \mathrm{~mm} \times 4.6 \mathrm{~mm}$ (i.d.), $5 \mu \mathrm{m}$ ] columns, individually. Separations were conducted using an isocratic elution with solvent A (isopropanol or $n$-butanol) and 
solvent B (hexane) under normal-phase condition. As for reverse-phase HPLC, the mobile phase was isocratic solvent A (methanol or acetonitrile) and solvent B (water). In each run, $20 \mu \mathrm{L}$ of the sample was injected and the flow rate was $0.8 \mathrm{~mL} / \mathrm{min}$ with the detection wavelength at $220 \mathrm{~nm}$. For thermodynamic study, the column temperature was changed from $10^{\circ} \mathrm{C}$ to $40{ }^{\circ} \mathrm{C}$.

\subsection{Method Validation}

Parameters including linearity, matrix effect, accuracy, precision, limit of detection (LOD), limit of quantitation (LOQ) and stability were used to assess the performance of the analytical method. The linearity of the method was studied by analyzing the blank standard and the matrix-matched standard at six $(0.05,0.5,1,2,5$, and $10 \mathrm{mg} / \mathrm{L})$ concentrations. Matrix effects were evaluated through comparing the slopes of the calibration curves obtained in matrix and in solvent. The linearity was the linear regression of etoxazole enantiomer area versus the injected concentration. The LOD was defined as the etoxazole enantiomer concentration that produced a signal-to-noise $(\mathrm{S} / \mathrm{N})$ ratio of 3 , while the LOQ was the concentration that produced an $\mathrm{S} / \mathrm{N}$ ratio of 10 . The recoveries and relative standard deviation (RSD) were adopted to assess the accuracy and precision of the developed analytical method, respectively. The stability of etoxazole stock solution was checked monthly and it was found that etoxazole was stable for at least three months at $-20^{\circ} \mathrm{C}$.

\subsection{Sample Preparation}

Homogenized samples (5 g) of cucumber, cabbage, tomato, and soil were thawed in $50 \mathrm{~mL}$ polypropylene centrifuge tubes at room temperature. In total, $25 \mathrm{~mL}$ of ethyl acetate, $1 \mathrm{~g}$ of sodium chloride, and $3 \mathrm{~g}$ of anhydrous sodium sulfate were added to the tube. The mixture was shaken for $20 \mathrm{~min}$ at $25^{\circ} \mathrm{C}$ with $280 \mathrm{rpm}$ rotational speed in a constant temperature oscillator, exposed to ultrasonic vibration for $10 \mathrm{~min}$, and then centrifuged at $3500 \mathrm{rpm}$ for $5 \mathrm{~min}$. The extract was filtered through $5 \mathrm{~g}$ of anhydrous sodium sulfate for dehydration. All the extraction steps were repeated with another $25 \mathrm{~mL}$ of ethyl acetate. The combined extracts were evaporated to near dryness using a rotary vacuum evaporator at $40{ }^{\circ} \mathrm{C}$ and reconstituted in $1.0 \mathrm{~mL}$ of acetonitrile. The resulting residue was filtered through a $0.22 \mu \mathrm{m}$ filter and transferred into a $2 \mathrm{~mL}$ sample vial for reverse-phase chiral HPLC analysis. Five replicates were performed for each fortification level.

\subsection{Data Analysis}

Separation parameters were calculated using the following equations: retention factor $\left(k=\left(t-t_{0}\right) / t_{0}\right)$, separation factor $\left(\alpha=k_{2} / k_{1}\right)$, and resolution factor $\left(R_{\mathrm{S}}=\left(2\left(t_{2}-t_{1}\right) /\left(w_{1}+w_{2}\right)\right)\right)$, where $t_{0}$ is the void time, $t$ is the retention time, $k$ is the retention factor, and $w$ is the peak width of etoxazole enantiomers.

In order to study the thermodynamic effects on etoxazole enantiomers separation, the retention factor $(k)$ and separation factor $(\alpha)$ obtained at different temperatures were used to calculate the standard enthalpy $(\Delta H)$ and entropy $(\Delta S)$ based on van't Hoff equation.

$$
\begin{gathered}
\ln k=-\frac{\Delta H}{R T}+\frac{\Delta S}{R}+\ln \varphi \\
\ln \alpha=-\frac{\Delta \Delta H}{R T}+\frac{\Delta \Delta S}{R}
\end{gathered}
$$

where $R$ is the universal gas constant $(8.314 \mathrm{~J} / \mathrm{mol} \mathrm{K}), T$ is the absolute temperature, $\varphi$ is the phase ratio, $\Delta H$ represents the molecular enthalpy, and $\Delta S$ is the molecular entropy of enantiomers between the mobile phase and the chiral stationary phase. $\Delta \Delta H$ represents the value of $\Delta H_{2}-\Delta H_{1}$ and $\Delta \Delta S$ represents the value of $\Delta S_{2}-\Delta S_{1}$. The values of $-\Delta H / R$ and $(\Delta S / R+\ln \varphi)$ could be calculated from the slope and intercept based on Equation (1). Likewise, the values of $-\Delta \Delta H / R$ and $\Delta \Delta S / R$ could also be obtained from the slope and intercept according to Equation (2). 


\section{Conclusions}

In the context of this study, the chiral separation of etoxazole enantiomers on Lux Cellulose-1, Lux Cellulose-3, Chiralpak IC, and Chiralpak AD chiral columns was fully investigated by normal-phase and reverse-phase HPLC. The effects of the chiral stationary phase, mobile phase component, mobile phase ratio, and temperature on separation resolution were carefully investigated. Etoxazole enantiomers were baseline separated on Lux Cellulose-1, Chiralpak IC, Chiralpak AD chiral columns, and partially separated on the Lux Cellulose- 3 chiral column under normal-phase HPLC. Furthermore, complete separation on Lux Cellulose-1, Chiralpak IC columns, and partial separation on Chiralpak AD were obtained under reverse-phase HPLC. Normal-phase HPLC presented better separation resolution for etoxazole enantiomers than reverse-phase HPLC. Thermodynamic parameters, including $\Delta H$ and $\Delta S$, were calculated based on temperature change from $10^{\circ} \mathrm{C}$ to $40^{\circ} \mathrm{C}$. Moreover, the optimized method was successfully applied to determination of etoxazole enantiomers in cucumber, cabbage, tomato, and soil. Such results systematically compared the separation efficiency of etoxazole enantiomers under normal-phase and reverse-phase conditions, and contribute to the comprehensive environmental risk assessment of etoxazole at the enantiomer level.

Supplementary Materials: The following are available online: Table S1: Effects of temperature on etoxazole separation with four chiral columns; Table S2: Linearity and matrix effect of etoxazole enantiomers in different matrix; Figure S1 Chiral resolution chromatograms of etoxazole enantiomers on Chiralpak $\mathrm{AD}\left(\mathrm{ACN} / \mathrm{H}_{2} \mathrm{O}, \mathrm{A}\right.$ 90/10, B 80/20, C 70/30 and D 60/40), Lux cellulose-1 (MEOH/ $\mathrm{H}_{2} \mathrm{O}$, E 100/0, F 95/5, G 90/10 and H 85/15), Chiralpak AD (HEX/IPA, I 90/10, J 80/20, K 70/30 and L 60/40), and Lux cellulose-1 (HEX/IPA, M 98/2, N 95/5, O 90/10 and P 85/15) columns.

Author Contributions: Conceptualization, P.Z. and L.H.; methodology, S.W.; software, D.S.; validation, D.S., Y.X. and J.W.; formal analysis, F.Y.; investigation, Y.X.; resources, L.H.; data curation, Y.H. and P.Z.; writing-original draft preparation, Y.H.; writing-review and editing, P.Z.; visualization, S.W.; supervision, P.Z.; project administration, P.Z.; funding acquisition, P.Z. All authors have read and agreed to the published version of the manuscript.

Funding: This research was funded by the National Natural Science Foundation of China (31801745), Natural Science Foundation of Chongqing, China (cstc2019jcyj-msxmX0403) and Fundamental Research Funds for the Central Universities (XDJK2020B061).

Conflicts of Interest: The authors declare no conflict of interest. The funders had no role in the writing of the manuscript and in the decision to publish the results.

\begin{tabular}{|c|c|}
\hline \multicolumn{2}{|c|}{ Abbreviations } \\
\hline HPLC & high-performance liquid chromatography \\
\hline CSP & chiral stationary phase \\
\hline GC & gas chromatography \\
\hline LOD & limit of detection \\
\hline RSD & relative standard deviation. \\
\hline
\end{tabular}

\section{References}

1. Jeschke, P. Current status of chirality in agrochemicals. Pest Manag. Sci. 2018, 74, 2389-2404. [CrossRef] [PubMed]

2. Williams, A. Opportunities for chiral agrochemicals. Pest Manag. Sci. 1996, 46, 3-9. [CrossRef]

3. Chang, W.; Nie, J.; Yan, Z.; Wang, Y.; Farooq, S. Systemic Stereoselectivity Study of Etoxazole: Stereoselective Bioactivity, Acute Toxicity, and Environmental Behavior in Fruits and Soils. J. Agric. Food Chem. 2019, 67, 6708-6715. [CrossRef] [PubMed]

4. Zhang, Q.; Hua, X.; Shi, H.-Y.; Liu, J.-S.; Tian, M.-M.; Wang, M. Enantioselective bioactivity, acute toxicity and dissipation in vegetables of the chiral triazole fungicide flutriafol. J. Hazard. Mater. 2015, 284, 65-72. [CrossRef] [PubMed]

5. Sun, J.; Zhang, A.; Zhang, J.; Xie, X.; Liu, W. Enantiomeric Resolution and Growth-Retardant Activity in Rice Seedlings of Uniconazole. J. Agric. Food Chem. 2011, 60, 160-164. [CrossRef] [PubMed] 
6. Lin, K.; Liu, W.; Li, L.; Gan, J. Single and Joint Acute Toxicity of Isocarbophos Enantiomers toDaphnia magna. J. Agric. Food Chem. 2008, 56, 4273-4277. [CrossRef]

7. Wang, Y.; Xu, L.; Li, D.; Teng, M.; Zhang, R.; Zhou, Z.; Zhu, W. Enantioselective bioaccumulation of hexaconazole and its toxic effects in adult zebrafish (Danio rerio). Chemosphere 2015, 138, 798-805. [CrossRef] [PubMed]

8. Ribeiro, A.R.; Afonso, C.M.; Castro, P.M.; Tiritan, M.E. Enantioselective biodegradation of pharmaceuticals, alprenolol and propranolol, by an activated sludge inoculum. Ecotoxicol. Environ. Saf. 2013, 87, 108-114. [CrossRef] [PubMed]

9. Li, Y.; Dong, F.; Liu, X.; Xu, J.; Li, J.; Kong, Z.; Chen, X.; Liang, X.; Zheng, Y. Simultaneous enantioselective determination of triazole fungicides in soil and water by chiral liquid chromatography/tandem mass spectrometry. J. Chromatogr. A 2012, 1224, 51-60. [CrossRef] [PubMed]

10. Yao, Z.; Qian, M.; Zhang, H.; Nie, J.; Ye, J.; Li, Z. Etoxazole is Metabolized Enantioselectively in Liver Microsomes of Rat and Human in Vitro. Environ. Sci. Technol. 2016, 50, 9682-9688. [CrossRef] [PubMed]

11. Suzuki, J.; Ishida, T.; Kikuchi, Y.; Ito, Y.; Morikawa, C.; Tsukidate, Y.; Tanji, I.; Ota, Y.; Toda, K. Synthesis and Activity of Novel Acaricidal/Insecticidal 2, 4-Diphenyl-1, 3-oxazolines. J. Pestic. Sci. 2002, 27, 1-8. [CrossRef]

12. A Dekeyser, M. Acaricide mode of action. Pest Manag. Sci. 2005, 61, 103-110. [CrossRef] [PubMed]

13. Yao, Z.; Li, Z.G.; Zhuang, S.; Li, X.; Xu, M.; Lin, M.; Wang, Q.; Zhang, H. Enantioselective determination of acaricide etoxazole in orange pulp, peel, and whole orange by chiral liquid chromatography with tandem mass spectrometry. J. Sep. Sci. 2015, 38, 599-604. [CrossRef] [PubMed]

14. Malhat, F.M.; Badawy, H.; Barakat, D.; Saber, A. Determination of etoxazole residues in fruits and vegetables by SPE clean-up and HPLC-DAD. J. Environ. Sci. Heal. Part B 2013, 48, 331-335. [CrossRef]

15. Chen, H.; Li, W.; Guo, L.; Weng, H.; Wei, Y.; Guo, Q. Residue, dissipation, and safety evaluation of etoxazole and pyridaben in Goji berry under open-field conditions in the China's Qinghai-Tibet Plateau. Environ. Monit. Assess. 2019, 191, 517. [CrossRef]

16. Hwang, J.-I.; Kim, J.-E. Residual Patterns of Acaricides, Etoxazole and Flufenoxuron in Apples. Korean J. Pestic. Sci. 2014, 18, 61-68. [CrossRef]

17. Wang, P.; Jiang, S.; Liu, D.; Zhang, H.; Zhou, Z. Enantiomeric Resolution of Chiral Pesticides by High-Performance Liquid Chromatography. J. Agric. Food Chem. 2006, 54, 1577-1583. [CrossRef]

18. Yang, W.; Qiu, J.; Chen, T.; Yang, S.; Hou, S. Direct Enantioseparation of Nitrogen-heterocyclic Pesticides on Amylose-tris-(5-chloro-2-methylphenylcarbamate) by Reversed-Phase High-Performance Liquid Chromatography. Chirality 2012, 24, 1031-1036. [CrossRef] [PubMed]

19. Qiu, J.; Dai, S.; Zheng, C.; Yang, S.; Chai, T.; Bie, M. Enantiomeric separation of triazole fungicides with 3- $\mu \mathrm{m}$ and $5-\mu \mathrm{ml}$ particle chiral columns by reverse-phase high-performance liquid chromatography. Chirality 2011, 23, 479-486. [CrossRef]

20. Fox, S.; Strasdeit, H.; Haasmann, S.; Brückner, H. Gas chromatographic separation of stereoisomers of non-protein amino acids on modified $\gamma$-cyclodextrin stationary phase. J. Chromatogr. A 2015, 1411, 101-109. [CrossRef]

21. Fernandez, V.P.; Vega, E.D.; Chankvetadze, B.; Crego, A.L.; Garcia, M.A.; Marina, M.L. Evaluation of new cellulose-based chiral stationary phases Sepapak-2 and Sepapak-4 for the enantiomeric separation of pesticides by nano liquid chromatography and capillary electrochromatography. J. Chromatogr. A 2012, 1234, $22-31$. [CrossRef] [PubMed]

22. Dascalu, A.-E.; Ghinet, A.; Chankvetadze, B.; Lipka, E. Comparison of dimethylated and methylchlorinated amylose stationary phases, coated and covalently immobilized on silica, for the separation of some chiral compounds in supercritical fluid chromatography. J. Chromatogr. A 2020, 1621, 461053. [CrossRef]

23. Dascalu, A.-E.; Speybrouck, D.; Billamboz, M.; Corens, D.; Ghinet, A.; Lipka, E. Analytical and preparative enantioseparations in supercritical fluid chromatography using different brands of immobilized cellulose tris (3,5-dichlorophenylcarbamate) columns: Some differences. J. Chromatogr. A 2020, 1622, 461125. [CrossRef] [PubMed]

24. Dubey, R.; Bhushan, R. Enantioseparation by Thin-Layer Chromatography. In Chiral Separations: Methods and Protocols, 3rd ed.; Scriba, G.K.E., Ed.; Springer Science+Business Media, LLC: New York, NY, USA, 2019; Volume 1985, pp. 35-44. 
25. Marina, M.L.; Benito, I.; DiezMasa, J.C.; Gonzalez, M.J. Chiral separation of polychlorinated biphenyls by micellar electrokinetic chromatography with gamma-cyclodextrin as modifier in the separation buffer. Chromatographia 1996, 42, 269-272. [CrossRef]

26. Choy, T.M.H.; Chan, W.H.; Lee, A.W.; Huie, C.W. Stacking and separation of enantiomers by acetonitrile-salt mixtures in micellar electrokinetic chromatography. Electrophor. 2003, 24, 3116-3123. [CrossRef] [PubMed]

27. Ward, T.J.; Ward, K.D. Chiral Separations: Fundamental Review 2010. Anal. Chem. 2010, 82, 4712-4722. [CrossRef]

28. Liu, N.; Dong, F.; Xu, J.; Liu, X.; Chen, Z.; Pan, X.; Chen, X.; Zheng, Y. Enantioselective separation and pharmacokinetic dissipation of cyflumetofen in field soil by ultra-performance convergence chromatography with tandem mass spectrometry. J. Sep. Sci. 2016, 39, 1363-1370. [CrossRef] [PubMed]

29. Ye, J.; Wu, J.; Liu, W. Enantioselective separation and analysis of chiral pesticides by high-performance liquid chromatography. TrAC Trends Anal. Chem. 2009, 28, 1148-1163. [CrossRef]

30. Yan, J.; Zhang, R.; Wang, X.; Wang, Y.; Wang, D.; Zhou, Z.; Zhu, W. Enantiomeric Separation of Chiral Pesticides by Permethylated $\beta$-Cyclodextrin Stationary Phase in Reversed PhaseLiquid Chromatography. Chirality 2016, 28, 409-414. [CrossRef]

31. Sun, D.; Pang, J.; Fang, Q.; Zhou, Z.; Jiao, B.N. Stereoselective toxicity of etoxazole to MCF-7 cells and its dissipation behavior in citrus and soil. Environ. Sci. Pollut. Res. 2016, 23, 24731-24738. [CrossRef]

32. Sun, D.; Wang, Y.; Zhang, Q.; Pang, J. Investigation of etoxazole metabolites in citrus, soil and earthworms by ultra-performance liquid chromatography with time-of-flight mass spectrometry. Chemosphere 2019, 226, 782-790. [CrossRef] [PubMed]

33. Zhang, P.; Yu, Q.; He, Y.; Zhu, W.; Zhou, Z.; He, L. Chiral pyrethroid insecticide fenpropathrin and its metabolite: Enantiomeric separation and pharmacokinetic degradation in soils by reverse-phase high-performance liquid chromatography. Anal. Methods 2017, 9, 4439-4446. [CrossRef]

34. Wang, P.; Liu, D.; Jiang, S.; Xu, Y.; Gu, X.; Zhou, Z. The chiral resolution of pesticides on amylose-tris(3,5-dimethylphenylcarbamate) CSP by HPLC and the enantiomeric identification by circular dichroism. Chirality 2007, 20, 40-46. [CrossRef] [PubMed]

35. Zhang, P.; Yu, Q.; He, X.; Qian, K.; Xiao, W.; Xu, Z.; Li, T.; He, L. Enantiomeric separation of type I and type II pyrethroid insecticides with different chiral stationary phases by reversed-phase high-performance liquid chromatography. Chirality 2017, 30, 420-431. [CrossRef] [PubMed]

Sample Availability: Sample Availability: Not available.

(C) 2020 by the authors. Licensee MDPI, Basel, Switzerland. This article is an open access article distributed under the terms and conditions of the Creative Commons Attribution (CC BY) license (http://creativecommons.org/licenses/by/4.0/). 